\title{
Organizing Technological Interdependencies: A Coordination Perspective on the Firm
}

\author{
Kirsten Foss \\ LINK \\ Department of Industrial Economics and Strategy \\ Copenhagen Business School \\ Nansensgade 19,6 \\ 1366 Copenhagen $\mathrm{K}$ \\ Denmark \\ eskimp@cbs.dk
}

16 May 2000

\begin{abstract}
This paper develops a coordination perspective on the firm. The basic idea is to combine insights in the division of labor with insights into the allocation of property rights. Thus, a basic argument is that use rights over productive assets are necessary in order to accumulate the experience needed to perform improvements in production. Specialization in production accelerates the accumulation of skills from learning by doing in production. However, specialization introduces greater complexity and new kinds of tools and equipment and this in turn create uncertainty about the best way of coordinating the specialized and interdependent activities. The result may be bottlenecks in production and uneven development of components. Experimenting with the coordination of tasks is necessary in order to eliminate these problems. However, such experimentation is best facilitated by a certain structure of property rights. Coordination by direction provides a cheap way of conducting the experiments needed to collect information on how best to coordinate interdependent activities.
\end{abstract}

\section{Acknowledgments}

The comments of George Richardson, Peter Maskell, Nicolai Foss and an anonymous reviewer are gratefully acknowledged.

\section{Keywords}

Property rights, specialization in production, firm, boundaries, learning

\section{JEL classification}

D23, L22 


\section{Introduction}

"Unfortunately", Oliver Williamson (1985: 141) explains, “... the study of innovation is enormously complex". Therefore, he refrains from incorporating innovation and related issues - such as technical change, learning by doing, and changes in the division of labor - into his analysis of economic organization. Judging from the published output on the interaction between innovation, etc. and economic organization, most economists of organization have apparently agreed, although the works of Teece (1986) and Langlois and Robertson (1995) stand out as important exceptions.

Although the study of innovation is indeed complex, it is a main point of this paper that drawing upon key ideas of the innovation literature and related literatures allows for the development of a coordination perspective on the firm, one that is much more explicit about the production side of firms than is usual in the theory of economic organization. ${ }^{1}$ To be more specific, the present paper focuses attention on the issue of the accumulation of managerial knowledge that is required for the coordination of specialized production tasks. ${ }^{2}$ It is fair to say that economists of organization (e.g., formal "new" property rights theorists, transaction cost economists, principal-agent theorists) have paid relatively little attention to the production side of firms, including not only innovation, but also issues such as learning by doing, specialization, bottlenecks, and much else (Langlois and Foss 1999). It is a key point of this paper that directing attention to such issues brings added insight in economic organization.

\footnotetext{
${ }^{1}$ Although coordination, rather than the mitigation of problems stemming from opportunism and moral hazard, was key to Coase (1937) and later to Penrose (1959) (Loasby 1999, 2000), the issue has not received much attention in the recent economics of organization (Foss 1999).

2 A production perspective on firms arguably encompasses many more issues than the one addressed in this paper. For example, important issues may be how agents learn to conduct specialized production tasks, how specialized and partly tacit production knowledge is transferred between the agents who carry out the production tasks, or how this type of production knowledge influence the choice between hierarchical planning of production activities or adaptation based more on team-based and local decisions. While these are all interesting aspects of production, a full treatment is beyond the scope of this paper.
} 
Specifically, I explore the issue of the existence and boundaries of the firm in the context of increasing division of labor, technological interdependencies and coordination advantages in production. ${ }^{3}$ Perhaps somewhat surprising to some readers, I shall draw on the property rights perspective as developed by Coase (1960), Alchian (1965), Alchian and Demsetz (1972), Cheung (1983), and Barzel (1989) to focus and illuminate these issues. ${ }^{4}$ For example, I shall focus on how the allocation of use rights in a firm interacts with learning, incremental innovation, and specialization. When analysis concerns such issues, a micro-analytic perspective is required, and the property rights as developed by the above writers is one such perspective.

To get an idea of the main ideas of the analysis, briefly consider Coase (1937). Since this paper, we have known that the costs of coordination depend on the mode of coordination. But as Coase pointed out, the advantages of the firm mode over the market mode diminish as marginal costs of coordination increase with more tasks being coordinated within the boundaries of a firm. However, increasing marginal costs of coordination make room for competition between firms for the coordination of specialized tasks, creating a pattern of vertical specialization in the chain of production. This reduces overall cost of coordination relative to both coordination within one firm and pure market coordination. Now, Coase (1937) and virtually the whole of the post-Coasian economics of organization take the costs of coordinating various tasks as well as the extent of specialization in the economy as given and proceeds to analyze why not all transactions among specialized agents are coordinated in either firms or in open markets.

\footnotetext{
${ }^{3}$ Note that in this paper I make a distinction between the division of labor and specialization. The former refers to the sub-division of tasks inside firms, while the latter refers to the allocation of tasks between firms. See Richardson (1975).

${ }^{4}$ Note that these contributions differ in their thrust and insights from the more recent property rights perspective developed by Oliver Hart and his various co-workers (e.g., Grossman and Hart 1986; Hart 1991, 1995) (for an analysis of the differences, see Foss and Foss 2000a,b). Although I shall also make brief reference to the work of Hart, I concentrate mainly on the works of Coase, Alchian and Barzel.
} 
The point of departure in this paper is different, since I am interested in how continuous division of labor introduces new coordination problems and new opportunities for learning to coordinate the more specialized tasks through conducting experiments in production. In turn the accumulation of knowledge on how to coordinate more specialized tasks can bring down costs of production. I argue that different modes of economic organization such as firm and market organization influence the cost of accumulating the relevant knowledge needed to bring down costs of coordinating the specialized tasks. The existence and boundaries of the firm then may be understood in terms of low cost learning in coordination. ${ }^{5}$ In other words, as in Penrose (1959), production is seen as involving a discovery procedure, and some types of economic organization may be more efficient than other types for organizing different manifestations of this procedure.

The design of the paper is the following. I begin from some well-known ideas about specialization and learning in production and argue that these ideas can be interpreted in terms of property rights. For example, an agent's learning is dependent on how extensive use rights he has to the various assets he controls. And specialization itself may be thought of as a subdivision of use rights over assets, so that each agent holds rights over a more narrow set of assets or holds a more narrowly defined set of rights over the same assets (Section II, "Specialization: a Property Rights Interpretation"). However, continuous division of labor may introduce technical uncertainty and give rise to bottlenecks and problems of uneven development of components, particularly in complex production systems. I shall argue that the Coasion notion of firms in which managers are granted rights of control to direct resources is one solution to such problems. More specifically, the Coasian firm is a response to a combination of, one the one hand, ignorance about the best way of specifying rights and high measurement costs, which together result in imperfectly specified rights, and, on the other hand, high costs of

\footnotetext{
${ }^{5}$ Langlois and Robertson (1995) have a related aim. However, their approach is different from the one pursued here, since they are more taken up with analyzing continuous changes in transaction costs and the costs of making adaptation to unforeseen contingencies in the case of complex production systems.
} 
re-contracting. This makes it desirable to rely on explicitly incomplete contracts and the firm is a superior structure for performing "controlled experiments" with complex production technologies (Section III, "Coordination in Production"). Finally, I briefly inquire into how these ideas connect to the issue of the boundaries of the firm (Section IV, "Make or Buy Decisions: Taking Advantage of the Division of Labor").

In sum, the contributions of this paper are, first, to give a novel interpretation of the meaning of specialization in production, second, to suggest some novel and dynamic mechanisms, drawn from the production side of firms, that are useful for understanding economic organization. and, third, to develop a notion of firms as experimenting entities.

\section{Specialization: a Property Rights Interpretation}

\section{Specialization}

As a preliminary definition, an increase in the division of labor in production can be described as dividing the production of goods into more narrowly defined sub-tasks. The division of labor in production is, as Adam Smith pointed out in the first chapter of The Wealth of Nations, one of the main sources of productivity improvements. Specifically, he ascribes productivity gains to three aspects of the division of labor, namely 1) improvements in a worker's ability ("dexterity") to perform a task as it is repeated more often; 2) the time that is saved from avoiding having to switch from one task to another ("sauntering"); and 3) an improved ability of a worker to identify labor saving innovations. As Smith indicates, the subdivision of tasks is not the only characteristic of specialization; changes in tasks as new innovations are introduced are also important characteristics of the process of the "progressive division of labor" (cf. also Young 1928).

The division of labor and specialization in production are tightly interconnected themes. While the former refers to the subdivision of tasks involved 
in the production of a certain good, the latter refers to the creation of production units specialized in the production of certain goods. The two types of specialization are interconnected; thus, Yang and NG (1995) argue that economies of specialization may arise from economies of labor specialization. ${ }^{6}$ However, in their model, economies of division of labor do not emerge gradually. The benefits are fully known ex-ante to the division of labor and specialization in production. This is in contrast to Becker and Murphy (1992) who emphasize that economies of labor specialization are both a consequence and a cause of specialization in production.

The above models are set out in an equilibrium framework. The main concern of the authors is to establish the equilibrium amount of specialization under different assumptions about increasing returns to division of labor. The concern here is different, since the aim is to argue that coordination problems in complex production systems - indicating disequilibrium situations - are under certain conditions best handled by the firm and that the boundaries of the firm are also influenced by a changing division of labor. In other words, the benefits from an increased division of labor reveal themselves gradually as agents improve dexterity in carrying out the tasks and as the problems of how to coordinate the more specific and interdependent tasks are gradually solved. Moreover, the division of labor can never be completed in a short time, since both the accumulation of knowledge needed to solve the coordination problems and the identification of benefits from a further division of labor takes time. Thus, the choice between firm and market organization of tasks change as the tasks change and as knowledge of how to coordinate the specialized tasks is accumulated and new opportunities for further division of labor is discovered.

\footnotetext{
${ }^{6}$ Not all writers in this area distinguish between the division of labor and specialization. Adam Smith and Allyn Young did not. Thanks to an anonymous reviewer for pointing this out.
} 


\section{Learning by Doing}

The idea that learning by doing underlies productivity growth was reintroduced in economics by Kenneth Arrow (1962) in a famous paper that anticipates much of the recent "new growth theory" (Romer 1986). He suggested that the growth of knowledge that underlies economic growth could partly be explained as a function of learning in production, and that technical change

... can be ascribed to experience, that is, it is the very activity of production which gives rise to problems for which favorable responses are selected over time" (p.156).

Moreover, Arrow argued that learning associated with repetition of tasks is subject to diminishing returns, so that continuous improvements in dexterity are dependent upon continuous changes in the tasks. Clearly, such changes may stem from innovations that may be a result of increased experience in production.

That hands-on experience in production is a source of innovativeness is also an important overall conclusion that can be drawn from numerous studies of innovation and technological change (Rosenberg 1976; Sahal 1981; Nelson and Winter 1982). These studies point to the fact that the nature of activities and the characteristics of the techniques in use tend to focus attention on certain technical problems. For example, Rosenberg argues that most incremental improvements in products and production processes are closely connected to their physical characteristics. He uses the term "technological imperatives" to indicate how some opportunities for technological development present themselves as more or less evident. Complex technologies, he argues, create internal compulsions and pressures (i.e., "focusing devices") that focus attention on the elimination of bottlenecks in productions and incompatibilities in products.

In a much-cited contribution, Devendra Sahal (1981) presented a similar but more elaborated characterization of the sources of innovative opportunities. According to Sahal, technological development leads to the formation of systems where the increased complexity from the mutually dependent components sets the 
boundaries for further development. He examines the different types of innovative activity that underlie this kind of technological development. For example, he explains how changes in the scale of a complex production system are particularly likely to create problems requiring innovative responses. These problems may be divided into three kinds: 1) Problems due to uneven development in the components of the technology; 2) problems that arise because of the need for new materials; and 3) problems caused by a more complex structure of technology. Solving these problems result in innovations that change the structure of the product or the production process, introduce new materials, or combine different technologies into a new system with a more simple structure allowing for further improvements.

Three conclusions of interest in the present context emerge from the abovementioned literature. First, productivity gains often stem from a combination of improved dexterity and innovativeness. Second, improved dexterity as well as innovativeness is a function of experience in production. Third, productivity gains from innovations in, for example, the structure of technology or materials, and reductions of bottlenecks in production are based on experience that is shaped by the nature of the activities that are undertaken, and is thus specific to those activities.

The division of labor in production influences the scope for learning by doing on the part of individuals, because it implies that their accumulation of experience in production is limited to more specialized tasks. However, there is a trade-off here between the depth of learning and the scope of learning, since specialization also implies that, as tasks are repeated more often, deeper learning results. Moreover, specialization results in faster learning of skills. The division of labor by focusing the attention of individuals on much a more narrow set of tasks - may 
improve the rate of innovativeness with respect to the discovery of new ways of carrying out a task, or of improving tools and materials that are used. ${ }^{7}$

However, as I shall explain more thoroughly later, specialization in production may also create problems of bottlenecks and problems from uneven development of components. Of course, such problems reduce the benefits from specialization, unless some mechanism for coordinating the interdependent specialized tasks is implemented. Before I turn to a discussion of coordination, I discuss the relation between specialization, allocation of property rights and learning by doing.

\section{Property Rights}

The kind of property rights theory that is utilized in this paper is that associated with writers such as Coase (1960), Alchian (1965), Demsetz (1967), Cheung (1969, 1983), and Barzel (1989). It is important to stress that although the insights of these authors were all developed in the context of neoclassical price theory, their basic insights relating to, for example, different notions of property rights, are not logically committed to basic neoclassical assumptions, such as fully informed maximization and continuous market-clearing. Thus, basic property rights ideas are fully consistent with the emphasis on uncertainty, complexity, disequilibrium, and experimentation adopted in the present paper.

As is well known, the property rights approach emerged from the insight that the objects of exchange are not assets per se, but rather the rights to those assets (Coase 1960). Property rights are the rights agents hold over assets, such as physical, human, financial, and intellectual property assets. More specifically, private property rights include the following kinds of rights (Alchian 1965; Eggertson 1990):

\footnotetext{
7 The ability to solve technical problems may also depend on specialized technical and/or scientific knowledge. Becker and Murphy (1992) models this as exogenous defined increases in the marginal return from investments in the knowledge needed to carry out increasingly specialized tasks.
} 
1. Use rights, which define the potential uses of an asset.

2. Income rights, or the right to consume an asset.

3. Rights to exclude non-owners from access to assets.

4. Rights to transfer permanently to another party all the above mentioned rights over an asset - that is, to alienate or sell an assets.

Contracts, whether formal or informal, are used to define the rights to be transferred and the terms of transfer of rights. The exchange of rights is not costless. For example, often physical and human assets have different properties and may sometimes yield a number of different services depending on how the assets are used. In principle, although not in practice, each one of the properties and different uses of assets that are known to the transacting parties could be specified and be subject to negotiations between parties to a transaction. Moreover, use rights over different properties or uses of assets may be shared between individuals (Barzel 1989). To specify and to contract over the different possible uses of assets, which are known to the transacting parties, are clearly costly actions - more precisely, they involve transaction costs. In the property rights framework, transaction costs are conceptualized as the costs due to the "transfer, capture and protection of rights" (Barzel 1989: 2). When such costs exist, not all known uses of assets will be specified in contracts.

An important characteristic of property rights is the degree of preciseness with which they are delineated. For example, one may distinguish between specific and residual rights (Barzel 1989; Hart 1995). Specific rights are those rights that are specified in contracts and allocated between the transacting parties before any transaction takes place. Residual rights are those rights that are not constrained by stipulations in contracts or by the law. Both use and income rights can be either specific or residual. Residual income rights (i.e. residual claims) are the nonspecified income or pleasure a person can enjoy from using or alienating an asset (including his labor). Rights and obligations may be more or less clearly defined. 
For example, if all rights were truly perfectly defined, according to the Coase theorem (Coase 1960), this literally means that

- all possible uses of assets are fully known

- all returns from all uses of all assets are perfectly known

- all legitimate and illegitimate uses of assets are perfectly specified

- all this is perfectly enforceable.

If all rights are completely defined in this way, there cannot, by definition, arise any conflicts over the use of scarce resources or the returns from assets nor can any discoveries from learning by doing take place. All uses are already discovered and individuals do not need to have any discretion in the use of resources. Of course, this is a highly unrealistic situation. In actuality, all rights are far from perfectly defined.

The distinction between specific and residual rights is not completely clearcut. Sometimes only the right to decide between different kinds of uses of an asset is described as residual rights while rights to decide how to use an assets in a specific way is described as discretion (Alchian and Woodward 1988). High information costs and ignorance often imply that transacting parties voluntarily leave rights over certain properties of an asset unspecified. For example, to completely specify all rights to use a computer requires full knowledge of all possible uses and all the different ways in which the computer may be operated, as well as a detailed listing of these uses. In addition, one would need to perform a tight surveillance of the users of the computer in order to enforce one's rights. Many rights over a computer are therefore left unspecified, and the user of the computer is then capable of exercising some discretion in his decisions on how to use or operate the computer. ${ }^{8}$

Finally, rights to decide between some pre-specified uses of assets may be delegated to others (Jensen and Meckling 1992; Aghion and Tirole 1995). Rights to

\footnotetext{
8 As long as there is incentive compatibility, in the sense that discretionary behavior does not favor one party at the expense of another, rights most likely will remain unspecified.
} 
specify specific rights over physical assets, delegate and otherwise transfer rights over assets follow from formal ownership over assets, and in the case of labor from voluntary agreements to transfer these rights. In the following sections, I use the term "specific rights" to denote only the situation where rights are delineated in ways which do not allow for discretionary behavior. If discretionary behavior occurs, this is because some rights have been imperfectly specified or enforced. The difference between having discretion and holding residual rights over assets is that the latter case includes rights to unilaterally re-define and re-allocate (by delegation or otherwise) rights over assets which are not specified in contracts.

Traditionally the literature on economic organization has focused on transaction costs as the reason for discretion and residual rights. Notably, the argument is that the employment contract is left partly open because of prohibitively high costs of specifying in detail all rights and obligations of the employee in all future conceivable situations. Related to this, the authority relation is seen as arising from the presence of transaction costs, because in the presence of such costs, incomplete contracts can give rise to conflicts and disagreements over the uses of assets (Williamson 1985). Assigning the right to decide how assets should be used in situations that are not covered by the contract is often a low-cost way of resolving this problem. 
There is also another but in the literature on economic organization often neglected reason why rights may not be perfectly defined and why employment contracts are used. Agents may be ignorant of all the possible uses of assets. However, some agents may expect that new uses of assets can be discovered, for example, in learning by doing fashion and that such discoveries will be profitable. 9

\section{The Division of Labor, Learning by Doing, and Property Rights}

Given the preceding discussions of specialization and property rights, we may now combine these insights and conceptualize an increase in the division of labor in production in terms of property rights. A subdivision of use rights over assets, so that each agent engaged in production holds use rights over a more narrow set of assets or holds a more narrow set of use rights over the same assets. The latter case may imply that use rights over an asset are shared between individuals. The one kind of specialization does not preclude the other.

It should be noted that the kind of assets over which one holds use rights need not be the same with division of labor as without. In many instances an increase in the division of labor and specialization is accompanied by a shift from all-purpose tools to more specialized equipment. However, the introduction of more specific equipment and tools limits rights, because these have fewer different uses.

There is a connection between learning by doing and use rights. This connection is a consequence of the fact that learning by doing requires the exercise of use rights over assets. Moreover, the better-specified and easily monitored use

\footnotetext{
${ }^{9}$ Both the choice between different types of contracts and the structure of the contracts are seen as reflecting transaction costs only. Thus, stipulation in contracts of the types of services and the terms at which they are to be provided reflects the costs of drafting the contract, costs of monitoring and enforcing the stipulations and the efficient risk sharing. Ignorance of the kind of services that may be needed or can be provided is usually not included as an essential feature of the choice. One exception is Steven Cheung (1969) who argue that agents tend to choose more firm like (employment contracts) if they know that they do not know today what services they may need tomorrow. This is also Brian Loasby's interpretation of Coase (see Loasby 1999, 2000).
} 
rights are, the less able are those who use assets to experiment and the more constrained is their learning. If, for example, the manner in which a computer operator runs a program is pre-specified in a contract and easily monitored, his learning by doing may be limited to improving the speed with which he activates the keyboard. If he has greater discretion in deciding how to operate the program, he might have a greater opportunity for learning by experimenting. Such experimentation may result in labor saving innovations of the kind envisaged by Adam Smith and, perhaps, today by proponents of "the learning organization". ${ }^{10}$

However, discretionary behavior need not always result in productivity gains. This may, for example, be the case if there is strong technological interdependencies, so that the functional performance ${ }^{11}$ of a technology is greatly influence by the fit between parts and/or between activities. In such a case, discretionary behavior may result in bottlenecks or in uneven development of components. Basically these problems arise when those who deliver parts or carry out activities are not aware of the need for mutual adjustment between parts and activities. These problems can be ascribed to imperfectly specified rights over assets.

High information and enforcement costs provide a reason why not all rights are well specified; however, ignorance is another equally good reason why rights

\footnotetext{
${ }^{10}$ Improvements in dexterity and innovativeness do not come about unless individuals also have the incentives to bring about these improvements. How these incentives are provided is beyond the scope of this paper. However, notice that with higher degrees of discretion an individual also has more room for shirking or otherwise appropriate a greater value from the use of an asset. The allocation of residual income rights from the use of an asset can be a powerful mean of reducing such rent-seeking behavior. Team problems (Alchian and Demsetz 1972) is an example of problems which arise because individuals have discretion. A similar problem exists in the production of complex products with may parts where it is only possible to test the quality of the product if all components are in place and working (David 1987). Each supplier of parts may then have incentives to exercise discretion and shirk on the quality of their output. In these cases a more complete realization of the advantages of specialization in production may require specialization in monitoring.

11 I use the term "functional performance of a technology" in accordance with Sahal (1981) as the objectively measured performance of a technology. As examples Sahal mentions the thermal efficiency of an electric power plant defined as the ratio of the electrical to the total thermal output of the fuel or the horse-power -hour per gallon of fuel or the horse-power-to-weight ratio of a tractor.
} 
are left unspecified. ${ }^{12}$ In this connection it is important to note that ignorance may be linked to increased division of labor in production and that such ignorance may be reflected in bottlenecks and uneven development of components. For example, it may take time to discover how best to sequence or conduct various activities when subdivision of rights over assets leads to increased complexity and interdependence between tasks. Moreover, specialization and growth of markets may give way for the introduction of new kinds of specialized tools and large scale equipment which in turn may introduce new problems of how to utilize capacity effectively (Ames and Rosenberg 1965; Leijonhufvud 1986). Finally, when ignorance is a characteristic of the process of redefining tasks and implementing new equipment, it is likely that some individuals will come to enjoy too large degrees of discretion in their exercise of use rights so that the conduction of their various tasks become uncoordinated. This, in turn, may result in innovations that may cause uneven development of tools, equipment and components.

Problems of bottlenecks and uneven development of components thus arise because many of the valuable dimensions of assets only become apparent from experimenting with the use of the assets. This make it is difficult or perhaps even impossible to specify all valued dimensions and uses of assets prior to an increase in the division of labor. ${ }^{13}$ Even if important dimensions can be specified it may be difficult to allocate these specific rights in ways which ensure the best use of assets. This may, for example, be the case with the time and place dimension of assets where some allocations result in excess stocks of intermediate products or in idle assets.

\footnotetext{
12 Thus, the preciseness with which use rights are specified depend on the benefit in terms of learning from discretionary actions on the one hand and the costs that may arise due to moral hazard and a lack of coordination on the other hand. Finally this is subject to the constraints of knowledge of the various uses and the transaction costs involved in specifying and monitoring the various tasks.

13 To confuse matters a bit the elimination of bottlenecks may imply the implementation of a technique in which many previously separate tasks are integrated into one production step. However, often knowledge based on learning in coordination is embodied into the technology.
} 
Solving problems that arise from technological interdependencies is an important source of innovative improvements (as pointed out by Rosenberg 1976 and Sahal 1981). However, such innovations do not emerge because of increased division of labor, but because of an ongoing learning with respect to coordination of tasks. From the literature on innovation studies it appears that much of this learning depends on the accumulation of hands on experience from experimenting whit different ways of laying out production tasks. The question then arises: What institutional set-up best provides for experimentation and accumulation of experience in the coordination of tasks?

In the following section I argue that the solution to coordination problems which manifest themselves as bottlenecks and uneven development of components is the Coasian firm in which managers (and/or owners) direct the use of resources. I also argue that the one important function of the Coasian firm in a specialized economy can be ascribed to its ability to reduce the transaction costs involved in setting up and conducting experiment. In situations characterized by high measurement costs and ignorance the high costs of recontracting will making it desirable to rely on explicitly open-ended contracts rather than seemingly complete contracts. In other words, with boundedly rational agents and technological uncertainty, there may be economic gains from experimenting in coordination and such experimentation may require the flexibility afforded by an open-ended contract for the provision of labor services and possibly combined with legal ownership of physical assets.

\section{Coordination and Experimentation in Production}

The need for social coordination arises as a consequence of interdependencies in consumption, between consumption and production and between production activities. These interdependencies follow from conflicting preferences over scarce resources or from technological interdependencies. Traditional price theory 
informs us that under certain restrictive assumption, including the assumption of perfectly defined rights and zero transaction costs, prices provide sufficient information to choose between different uses of resources in a manner that at the same time optimize the utility of individuals and ensure social coordination, leaving no valuable resources idle. Firms in this stylized world simply are specialized units of production that produce for outsiders (Demsetz 1995: 8). ${ }^{14}$ Their "coordination tasks" consists of selecting the profit-maximizing quantities of inputs and outputs for the specialized production tasks they each carry out. In this world, there is no need for firms to consider the question of make or buy, since with perfect price information there are no gains from organizing one more or one less specialized task within a firm.

\section{Specialization and Coordination}

It is, however, a commonplace notion that there is a trade-off between the advantages from specialization and the costs of coordinating increasingly specialized tasks. One likely explanation of this is that real world markets do not function as smoothly as portrayed in the neoclassical price theory. The use of real world markets may be particularly costly when further division of labor creates new unknown technological interdependencies that result in bottlenecks and uneven development of components.

Problems of bottlenecks and uneven development of components exist even if total self-sufficiency prevailed, since individuals producing for their own needs may be unaware of how best to carry out an activity or how to develop the technologies they use. The division of labor and specialization in production, however, is likely to magnify the problems because mutual adjustments now

\footnotetext{
14 As Loasby (2000) points out, the problem with this view is that it implicitly assumes that the existence of markets requires no explanation. To adequately deal with this issue would, however, require another paper.
} 
require awareness of what other individuals are doing. ${ }^{15}$ If, in addition the functionality of a technology is strongly dependent on the external conditions for carrying out the tasks, there may be a permanent need for mutual adjustments. As knowledge is accumulated from learning by doing new ways of specifying use rights will emerge. In fact, the process of discovery in an learning by doing fashion may itself require continuous adaptation that involve the redefinition and reallocation of use rights between the agents.

With an extensive division of labor and strong interdependence between tasks it may be economically efficient to rely on a centrally developed and directed experimental set up rather than on decentralized negotiations over different experimental set ups. Decentralized negotiations and specialization in production makes it is necessary to obtain the consent of many parties, each holding a sub-set of rights over the relevant assets needed to operate the technology in order to continually reallocate or re-delineate rights in a way that improves the functional performance of technologies. Therefore, when further divisions of labor introduces technological independence in production, reaching coordination requires the utilization of a complementary institution to arm-length markets transactions in order to solve the problems of mutual adjustment between individuals carrying out interdependent tasks. It shall be argued that the Coasian firm is such an institution.

\footnotetext{
15 The benchmark for improving coordination by re-arranging rights over human and physical assets could be the functional performance of a technology without specialization in production. However, a comparison of the functional performance of technologies in situation of specialization and no specialization is complicated by the fact that it is most likely not the same technologies which are used in both situation. A comparison between the coordination that could have been achieved in a perfect (Walrasian) market characterized by a given degree of specialization and given technologies is another possible solution. However, in a timeless world of zero transaction costs there are only very few limits to the division of labor and tasks are likely be very specialized. To derive the optimal coordination by comparing an unrealistic Walrasian market model with a real situation is to commit an error that may result in too great investments in improving coordination. All one can say then is that an investment in the improvement in coordination is efficient if the resources invested in bringing about the improvement is the best possible investment at the time at which it is contemplated.
} 


\section{A Property Rights Perspective on "The Nature of the Firm"}

Since the publication of "The Nature of the Firm", increasing attention has indeed been focused on how costs of coordination vary with the mode of coordination, with firms being an alternative coordination mechanism to the market mechanism. Here I interpret Coase's analysis of the nature of the firm in terms of property rights. I argue that Coase's notion of firms can be viewed as a solution to problems of coordination in situations where use rights over assets cannot be perfectly specified and allocated in manners which ensures the functionality of technologies. Such situations may occur because individuals face uncertainty and because they have only limited computational capacity making it to difficult for them to specify use rights in ways that solve problems of interdependencies ex-ante to a further division of labor. One of the reasons why managed coordination may be advantageous to price coordination is because the former reduces the costs of learning to coordinate technologically interdependent tasks.

Coase (1937) uses coordination costs to explain why in an economy with a given degree of specialization in production markets and firms co-exist as alternative modes of coordination. The reason for the existence of firms is that there are costs of using the price mechanism and that "[ $t$ ]he most obvious cost of "organizing" production through the price mechanism is that of discovering what the relevant prices are" (Coase 1937: 21; my emph.). With high market cost (later termed transaction costs), the market mode of coordination is substituted by a firm mode of co-ordination based on managerial decisions. While Coase (1937) does not explicitly suggest that uncertainty is a reason why it may be costly to discover "the relevant prices" or why managed direction may be less costly than open market transactions, uncertainty seem to play an important role in his explanation of the need of open-ended contracts such as employment contracts. According to Coase an employment contract is preferred "... owing to the difficulty of forecasting, the longer the period of the contract is for the supply of the commodity or service, the less possible, and indeed, the less desirable it is for the person 
purchasing to specify what the other contracting party is expected to do" (Coase 1937: 21).

Stated in the terminology of property rights there are high costs of specifying the valued attributes of assets in all future states; this results in some rights over valued attributes of assets being left unspecified. When the coordination between factors is subject to changes in external factors (contingencies) that cannot be specified ex ante, continuos redirection of resources and re-planning taking advantage of the dimensions of time and place of assets will be necessary in order to avoid bottlenecks. ${ }^{16} 17$ Managed direction of resources may thus substitute for price direction of resources when parties to transactions realize that contingencies of different sorts may interrupt the timing and sequencing of interdependent activities (for a recent treatment, see Wernerfelt 1997).

An arbitrageur holding stocks of assets also makes his money from superior knowledge about the value of the unspecified attributes of time and place. The employment contract could be interpreted as providing a stock of labor services that within limits could be allocated to different uses by the direction of a manager in response to unforeseen contingencies (Coase 1937). Managers then play the role of arbitrageurs holding stocks of labor services in order to take advantages of superior knowledge of the time and place property of labor services.

\footnotetext{
${ }^{16}$ Bargaining as a way of determining the prices may be very costly if each contingent plan involves many interdependent tasks that require close contacts between those who carry out the activities. As explained by Rosen (1991) in the case of team effects (joint production), a pricing scheme which solves the coordination problem of time and place will be extremely complex to work out. Moreover, "...to calculate and implement this solution requires full knowledge of the underlying technology and productivity of team members in the first place" (p.81). And since errors in prices can be more costly than errors in the allocation of activities and time, it may be advantageous to rely on a manager to perform the allocation of time and workers to tasks and then let the manager monitor the activities. The importance of managerial direction diminishes if the technology becomes fully known to all.

${ }^{17}$ In a system of production the timing of a particular sequence of activities is a way of reducing costs of idle labor or machinery and costs due to the building up of stocks of intermediate products. The advantage to tighter integration of different steps in the process is the costs saved on stocks and idle resources. These advantages have to be measured against the cost of failure or irregularities in strongly interdependent systems. Firms therefore may hold stocks of input in order to reduce these latter costs.
} 
Now, arbitrageurs only need to bear the cost of stocks if they can not appropriate the benefits of their knowledge of time and place by selling this information. Two factors may explain why it is not always feasible to sell information about time and place dimensions of assets. First, there is the wellknown problem of information as a public good which, if revealed before the transaction, cannot be protected from capture (Arrow, 1962). Secondly, negotiations may take longer time than direction by orders and because of this, the opportunity for profitable action may be gone. ${ }^{18}$

However, to Coase high costs of discovering the relevant contingencies are not a sufficient factor in explaining why firms exist because for each unforeseen contingency one discovers one might be able to negotiate a new contract. Therefore, firms exist only if there is also "... costs of negotiating and concluding a separate contract for each exchange transaction that takes place on a market (ibid.: 21). These costs are reduced "... if the factor, for a certain remuneration (which may be fixed or fluctuating), agrees to obey the direction of an entrepreneur within certain limits (ibid.: 21, emph. in original). Coase (1937) thus, used the employeremployee relationship as the archetype of the firm where managers rights to direct resources within certain limits provide a low cost way of filling the holes in the open-ended employment contract.

Much later, Coase (1991) observed that already at the time when he wrote "The Nature of the Firms", he was aware that the analogy between the employment contract and the firm could give an incomplete picture of the nature of the firm. For one thing “... a firm may imply control over another person's property as well as over their labor" (p.64), an amendment which figured in a footnote of the original paper indicating that firms may also posses use rights over rented assets. Coase (1991), however, also points to a second amendment to the

\footnotetext{
${ }^{18}$ In some productions, time is not just valuable but in fact critical to the quality of products. In pea production for example, the timing of harvest is very important in order to fulfill the goals of high capacity utilizing of the pea processing equipment and avoid quality losses from perishability of peas. For the harvest period, pea processing firms therefore may acquire from the farmers of peas the use rights over peas and fields in order to plan and decide on all matters concerning the harvest of peas.
} 
original article. He draws attention to a lecture note from 1934 in which he states that "... a full firm relationship will not come about unless several such (incomplete) contracts are made with people and for things which cooperate with one another" (Coase 1991: 64). The latter amendment can be interpreted to mean that managerial decisions fill the holes of open-ended contracts in cases where coordination of large number of factors that cooperate with each other is required. This is exactly the situation that comes into existence when further divisions of labor in production result in technological interdependencies between many tasks.

The inability to specify future states of the world, need not be the only explanation of why managed coordination is preferred to price coordination. The importance of managed direction of interdependent assets may also be motivated by endogenously created technological uncertainty, which arises when further division of labor alters tasks and create new unknown interdependencies between tasks. For example, the complexity of technologies may make it difficult to know in advance the particular requirements for efficient coordination. In fact, with a great deal of interdependence in a complex system, the best time and place to use an asset depend on the specification for the uses of all other assets that are needed in the production. Managed coordination is therefore important even if there are no unforeseeable contingencies that require adjustment in tasks. Firms thus exist as parallel institutions to markets in order to capture the value of the unspecified attributes of assets. 19

\footnotetext{
19 Ownership of assets, however, may also be a cheap way of internalizing externalities. When an owner wants to enjoy the benefits of labor specialization he is required to delegate use rights to agents. If he has full knowledge of all the uses of the assets that he owns and of all the consequences of the various uses he can delegate use rights in ways that minimize the negative (economic) consequences of externalities. To avoid some of the costs of externalities which arise with interdependent activities and team production managers may "regulate" the use of assets within firms by for example, defining strict limits of authority of decision takers or by simply forbidding certain uses of assets. To the extent that he is unaware of all the possible externalities an owner/manager will have to conduct various experiments not only in ways of producing but also in the selective grant of authority.
} 
To sum up, firms exists only if there is both high costs of discovering the relevant prices and if these costs cannot be reduced by contracting for this information. The latter may be the case where there are numerous interdependencies between owners of resources. This makes it costly to carry out the needed rearrangement of tasks to take advantage of new information about states of the world. Firms then save transaction costs by substituting many independently determined contingent contracts by managed directions. This may be taken to be the essence of Coase (1937). To this I add the transaction cost that may be saved when endogenously created technological uncertainty and complexity require sequential delineation and reallocation of rights over assets as a way of gradually improving the functional performance of technologies. The role of a managers thus are different from that of an arbitrageurs since the former engage in learning activities that involve the experimentation with different allocations of use rights in order to discover profit opportunities.

For managed direction of resources to be efficient, it is required that managers are at least as qualified in discovering the relevant prices (that is, find the opportunity costs of different uses of assets) as independent contractors would be. Otherwise, costs of transacting may be saved at the expense of efficiency in the use of resources. If managers have better knowledge or information about the valuable uses of resources compared to other agents, managers have a natural ownership advantage over resources. Such an advantage explains the single person firm, but not necessarily why managers in order to take advantage of this knowledge hire employees who are prepared to take orders within certain limits. "Managers" could as well rent the labor time of another agent in return for the exercise of certain well-specified task.

Arguably, managers stand a good chance of acquiring superior information about the opportunity costs of different use rights over assets that make up a complex technology. From the literature on incremental innovations, it is apparent that the solution to problems of bottlenecks and uneven development in components are based on experience in production and development. I shall now 
argue that this experience is probably more easily accumulated within the boundaries of firms.

One might expect this learning process to be less costly to organize within rather than across the boundaries of firms because managers, who hold residual rights over assets — including rights to re-define and reallocate specific rights are able to conduct controlled experiments without continuously having to renegotiate contracts. This saves time and ink-costs. Moreover, due to the uncertainty surrounding the outcome of various experimental set-ups, independent contractors will have different subjective valuations of different experimental strategies that can be pursued. This is likely to complicate the bargaining process. ${ }^{20}$ In contrast, within a firm managers can unilaterally create a "controlled" experiment in which they only change some aspects of the tasks in order to trace the effects of some specific re-arrangements of rights. Finally, coordinating interdependent tasks within the boundaries of a firm may provide managers with a more complete picture of the nature of interdependencies. This information is not only important in relation to eliminating bottlenecks, but also in relation to avoiding problems of uneven development of components by setting up interface standards and other more permanent solutions.

\section{Other Determinants of the "Costs of Discovering the Relevant Prices"}

In the previous section uncertainty and complexity were seen as determinants of the costs of discovering "the relevant prices." As many contributions to the economics of organization have made clear, there may be many other reasons why there are high costs of discovering the relevant prices and some of these reasons may become more predominant with increased specialization in production. Different modern theories of the firm put emphasis on different costs of transacting — such as measurement costs, contracting costs and costs of enforcing rights over 
assets - in explaining the existence and boundaries of firms. This section provides a brief overview of some of the various arguments presented in the literature, and relates them to the arguments of this paper.

Taken by them selves high costs of discovering what the relevant prices are need not require the existence of firms. For example, high measurement costs may make it costly to determine the valued characteristics of assets and this may cause problems of excess sorting and of shirking on quality (Barzel 1982). Managed direction of assets may not always be the most effective means of solving such problems. Other arrangements, such as product guarantees, quality classes and investments in brand name capital are often better suited. However, specialization in production may create other kinds of problems related to high measurement costs. One of the advantages of specialization between production and consumption is the ability to take advantage of economies of scale in equipment. In order to realize such advantages, many individuals may have to cooperate in order to operate the equipment. If tasks are not perfectly specified in terms of each individual's rights to use different attributes of the equipment or if such rights cannot be enforced, it is possible that each individual will exercise discretion and try to gain at the expense of others.

If, for example, it is difficult to determine how much the operation of each individual contributes to the wear and tear of the equipment there is a problem of common property and this imply that there is likely to be insufficient incentives for investments in maintenance. ${ }^{21}$ Therefore according to Barzel (1989), “[a]ttributes susceptible to serious common-property problems, such as equipment lubrication, will tend to be owned by organizations created to control these problems" (p.58). One way of controlling such problems, which involves an organization, is to use a

\footnotetext{
${ }^{20}$ In this connection wage contracts may be an efficient way of sharing risks from experimenting, putting the entire burden of risk on the shoulders of those who carry out experiments (cf. Knight 1921).

${ }^{21}$ As explained by Barzel (1989) the common property problem disappears if the equipment is scaled down to fit a single operator producing an identifiable output. Some mean of coordinating individual operators is still needed but with each producing an identifiable output contracting in market may provide the coordination.
} 
fixed wage contract in which workers are remunerated for their time rather than their output. But workers receiving specific income for a specific amount of time have no incentives to devise ways of exercising use rights over assets that would generate utility. Thus, when fixed wage contracts are used, monitoring of effort will be needed to induce effort and managers will have to specify the tasks to be performed (Barzel 1989).

Specialization in production creates a similar problem if there are high costs of determining the level of effort provided by individuals. In particular, where cooperation in teams is needed between different individuals in order to realize rents on their labor services from producing a given output, problems of common property may occur. This is because each individual is able to exercise discretion in providing his labor services but only bears part of the costs. The solution to such team problems is to set up an organization that will economize on metering costs and an allocation of rewards which is more in accord with the effort delivered (Alchian and Demsetz 1972).22 A monitor specializing 23 in metering effort and holding rights to residual income, to alter membership of the team and to sell all their rights may provide such a solution.

A second type of explanation of why firms exist emphasizes how high information costs or uncertainty makes it difficult to enforce one's rights over assets (e.g. Williamson 1975, 1985; Klein, Crawford, and Alchian 1978; Hart $(1991,1995)$. According to this literature, there is a strong correlation between asset specificity and contracting failure, and this causes inefficiencies because valuable

\footnotetext{
${ }^{22}$ According to Alchian and Demsetz (1972) team production is production in which " 1 ) several types of resources are used and 2) the product is not a sum of separable outputs of each cooperating resource. An additional factor creates a team organization problem - not all resources used in team production belong to one person" (p.779). The separate ownership over resource is motivated by such factors as risk aversion, the prohibition of slavery and sunk costs investments which make short term ownership to costly. However, the separation of ownership could also have been motivated by the possibility of realizing advantages of specialization in accumulating different complementary skills of production.

${ }^{23}$ Monitoring means to "... measure output performance, apportioning rewards, observing the input behavior of inputs as means of detecting or estimating their marginal productivity and giving assignments or instruction in what to do and how to do it" (Alchian and Demsetz 1972: 782; my emphasis). However, the reason for the latter kind of activity is left unexplained.
} 
transactions involving investments in transaction specific assets is not completed. In particular, it is assumed that; high costs of planning for all various contingencies; of describing future states and of communicating these plans to a third party makes it impossible to write complete contracts. Therefore, one cannot safeguard one's investments in specific assets with the aid of a third party (typically a court).

Specialization in production may make investments in specialized equipment and in specialized knowledge which have no alternative value outside a particular relation attractive. According to incomplete contract theories, undertaking such investments requires vertical integration so that firms can take on the role of enforcer of contracts. Williamson (1985), for example, describes firms as their own ultimate court of appeal. To Hart, the physical assets over which a legitimate owner has formal residual use rights define firms. Having residual use rights over assets provides the owner with a mean of enforcing contracts that would not be possible if transactions took place between different owners of assets.

These different explanations of firms have in common the idea that the best uses of resources are already known. This is because they take production theory as a appropriate for describing production, and thus assumes public knowledge of production sets and the availability of all relevant skills required for production (Langlois and Foss 1999; Loasby 1999). The problem is "simply" how to provide the right incentives for efficient exploitation of or investment in the assets in question. Monitoring and more advanced incentive schemes --than those that can be devised for re-contracting between independent individuals (with definite time horizons)-- help overcome such problems. However, direction by order giving is not a central element in the solution and the possibilities of learning to coordinate tasks is limited to improving one's skills as a monitor.

Each one of the above explanations of firms surely provides important insights into factors that influence the boundaries of firms that are complementary to the specialization story told in this paper. However, they do not give any account of why the boundaries of firms may changes over time. In the next 
section, I argue that opportunities for specialization advantages together with continuos learning in coordination within the boundaries of firms provides opportunities for continuos changes in the boundary of firms, thus adding a dynamic element to the economics of organization.

\section{Make or Buy Decisions: \\ Taking Advantage of the Division of Labor}

Coase (1937) explains why market and firms co-exists in a specialized economy. But after having established a reason for the existence of firms, Coase goes on to apply transaction costs analysis to determine the boundaries of firms. He argues that there are increasing costs to organizing more transaction within a firm and that this explains why not all transactions are carried out in one big firm. When increasing marginal costs of management leave room for other firms to come into existence, different subsets of production tasks will be organized in different firms.

Coase (1937) did not investigate the factors that would make the costs of organizing a particular subset of tasks lower for some firms than for others. However, such an analysis is important to make or buy decisions, because these kinds of decisions are seldom a question of making a choice between either a firm or open market transactions, but of organizing a subset of production tasks within one firm rather than another firm. In fact, Coase (1991) argues that "... if one is to explain the institutional structure of production in the system as a whole it is necessary to uncover the reasons why the costs of organizing particular activities differs among firms" (p.73), and these costs, according to Coase, "... may depend on the other activities that the firms are undertaking (p.67). ${ }^{24}$

\footnotetext{
${ }^{24}$ Coase (1937) mentions "... increasing opportunity costs due to the failure of entrepreneurs to make the best use of the factor of production" (p.23) as one of the reasons why there is a limit to the efficient size of a firm but not why some firms are more efficient in carrying out certain activities rather than other activities. Coase assumes that there are increasing opportunity costs of expanding
} 
A more in-depth understanding of why firms differ with respect to their costs of organizing different activities is important to the analysis of the "make or buy" decisions of firms. If firms are not equally good at coordinating the same types of tasks, this should influence where the boundaries of firms are placed. The arguments presented earlier suggests that learning by doing in production and coordination results in different abilities and thus different costs among firms with respect to the organization of different kinds of tasks. Make or buy decisions of firms must reflect these endogenous changes in production and coordination costs as employees and managers learn in production and coordination.

Based on the arguments presented earlier, the importance of learning in coordination depends on the extent and complexity of technological interdependencies in production activities. If specialization creates strong technological interdependencies, there will be advantages from learning to coordinate which favor organization within the boundaries of firms, at least until sufficient experimentation have resulted in the delineation of specific rights in manners which deals with these interdependencies.

The costs of organizing the interdependent tasks of course also needs to be considered when deciding on make or buy. These costs consists in increasing marginal management costs and bygone opportunities for taking advantage of further specialization in other tasks until coordination costs with the already obtained degrees of labor specialization have been reduced. Since accumulation of

the boundaries of a firm because "... the costs of losses through mistakes will increase with an increase in the spatial distribution of the transactions organized, in the dissimilarity of the transactions, and in the probability of changes in the relevant prices. As more transactions are organized by an entrepreneur, it would appear that the transactions would tend to be either different in kind or in different places" (p.25). Managers, in other words, have limited capacity to "discover the relevant prices" and this increases mistakes as more and more dissimilar transactions are organized in a firm (Richardson (1972) has a very similar argument for the boundaries of firms). Clearly, some of the problems of limited capacity of managers may be solved by delegation and selective intervention. However, as explained by Williamson (1985) there are unavoidable side effects of moving transactions into a hierarchy. According to Williamson these costs may not be off set by gains from reduced transaction costs unless some degree of assets specificity is involved. In my opinion the losses from integration may also be off-set by the flexibility afforded by the employment contract with respect to selective intervention in activities. However, in order to efficiently delegate responsibility a manager needs experience 
experience in coordination is often local and not transferable (except, possibly, at high costs) firms tend to persistently differ in their capabilities and this may explain a certain path dependency in the kind of activities firms undertake. In other words, it may be difficult for firms to buy the services they produce in house cheaper from suppliers (cf. also the analysis in Langlois and Robertson 1995).

Accumulation of experience in coordination may explain some of the cost differences between firms, but this is not the entire explanation. A different reason may be found in the fact that there are also advantages of specializing in knowledge (Loasby 1999). Managers in firms then may posses different scientific and technological knowledge and therefore have different abilities to perform experiments in coordination.

This explanation is in line with Demsetz (1991) who also argues that firms are not perfect substitutes in production of goods and services. According to Demsetz firms are specialized production entities each holding a different subset of the production knowledge needed to produce a consumption good. For specialization in knowledge to be productive, specialists need to be able to take advantage of other specialists' knowledge. Within firms coordination between specialists with different kinds of knowledge is achieved by giving orders. Following Demsetz, this is efficient because otherwise each specialist would have to learn what all other specialists already know. The boundaries of firms are shaped by the relative costs and advantages of putting specialized knowledge to use by means of order-giving or by means of selling goods accompanied by instruction on uses. The latter is advantageous when the best use of an asset does not strongly depend on it being used at a particular time and place.

Giving orders and producing goods embodying specialized knowledge is thus two different way of economizing with the costs of transferring knowledge. This explanation indicates that a decision to make or buy must also depend on the trade-off between taking advantage of low costs experimentation within the boundaries of a firm and taking advantage of specialized knowledge located in other firms. 
Finally, socially developed norms, rules and routines also reduce costs of coordination. Norms and routines make the behavior of others more predictable thus reducing the need for information required for the coordination of actions (Heiner 1983). In the terminology of property rights, norms and routines can be said to act as self-enforcing constraints on use rights. Such norms and routines certainly also play a great role in determining the costs of coordination in different firms and the decision to make rather than to buy may often be grounded on superior, non-imitable and non transferable routines which aids coordination in production. Norms and routines are not confined to firms; they may as well evolve as means of coordinating actions between independent contractors such as for example two different firms. In that case they also reduce costs of market transactions.

Firms need not have full information about all the interdependencies between tasks before they decide to buy rather than to make. Some of the experimental activities needed to improve the effective working of technologies can be organized by means of, for example, joint ventures, strategic alliances, complex long-term contracts, etc. In some of these arrangements the parties rely more on the use of prices and negotiations and in some more on directions as means of coordination. However, what distinguishes these arrangements from internal organization of the transactions is that they are based on agreements between legally independent agents - thus, the analysis in this paper of the choice between firm and market applies also to the analysis of the choice between firms and interfirm arrangements. The legally independent parties to an interfirm arrangement will have to reach an agreement on the terms of corporation and this often require that they possess some knowledge/beliefs about what the proper procedures are for the experimental activities. The choice between the various arrangements therefore must depend on the knowledge/beliefs the parties have of the relevant procedures for the completion of the experimental learning process since otherwise it may be very costly to reach an agreement (if possible at all). 


\section{Conclusion}

I have argued that learning in coordination within firms should be centered on ways of discovering the true opportunity costs of the use of assets where prices fail to provide the proper information. There are many reasons why price information fails to indicate these opportunity cost; I have focused on one in particular - the increasing interdependence among various tasks which follows from increased specialization in tasks. I have argued that a high degree of interdependence may make it impossible for managers ex ante to specify rights over assets and labor in such a way that that each sub-task fits optimally to all other tasks carried out.

For example, the problem of defining an optimal sequence of task in a complex systems of production may require more calculation capacity than is available in a supercomputer (Galloway 1996) ${ }^{25}$. In such cases improvements in allocation of rights require experimentation in the sequencing of tasks, which in turn requires sequential re-delineation and reallocation of specific use rights among those carrying out the various tasks. Managed coordination is likely to be less costly relative to arm-length bargaining partly because order-taking saves bargaining costs, partly because some specialized technological knowledge may be required in order to discover the opportunity costs (or shadow prices) of various subdivisions of tasks and the respective allocation of rights.

Increasing division of labor in production influences the boundaries of firms by creating opportunities for economic gains from learning to coordinate technologically interdependent tasks. However, since there are increasing marginal costs of coordinating more specialized tasks within the boundaries of a firm it may sometime be advantageous to out-source interdependent tasks in order to take advantage of further specialization in other tasks. Finally, the knowledge acquired in experimenting with coordination together with advantages of specialization in

\footnotetext{
${ }^{25}$ In describing the problem of scheduling batches in a 5 stage production process, Galloway (1996) writes " $[\mathrm{t}]$ he best schedule is the one which minimizes this idle time. Unfortunately, the only way to find the best schedule is by trial and error, and whit 20 batches there are $1.8 \times 10^{18}$ possible schedules. This problem is too large even for modern computers, so a simplifying assumption is frequently used (p.64).
} 
scientific and technical knowledge may explain the relative advantages of firms in organizing some particular tasks and these advantages must also be taken into account in the make and buy decision. 


\section{References}

Aghion, Philippe and Jean Tirole. (1995), "Some implications of growth for organizational form and ownership structure "European Economic Review, 39: 440-455.

Alchian, Armen A. (1965), "Some Economics of Property Rights," in idem. 1977. Economic Forces at Work, Indianapolis: Liberty Press.

Alchian, Armen A., and Harold Demsetz. (1972), "Production, Information Costs, and Economic Organization," American Economic Review 62(5): 772-795.

Alchian, Armen A. and Susan Woodward. (1988), “The Firm is Dead; Long Live the Firm," Journal of Economic Literature 26: 65-79.

Ames, Edward and Nathan Rosenberg. (1965), “The Progressive Division and Specialization of Industries," Development Studies 1: 363-383.

Arrow, Kenneth J. (1962), "Welfare and the Allocation of Resources for Invention. In: The Rate and Direction of Inventive Activity: Economic and Social factors. Princeton University press, Princeton :609-626.

Arrow, Kenneth J. (1962), "The Economic Implications of Learning by Doing," Review of Economic Studies 29: 155-173.

Barzel, Yoram. (1982), Measurement Costs and the Organization of Markets", Journal of Law and Economics 25: 27-48.

Barzel, Yoram. (1989), Economic Analysis of Property Rights, Cambridge: Cambridge University Press.

Becker, Gary S and Kevin M. Murphy. (1992), “The Division of Labor, Coordination costs, and Knowledge," The Quarterly Journal of Economics 107: 1137-1160.

Camacho, A. (1995), Division of Labor, Variability, Coordination, and the Theory of Firma and Markets, Dordrecht: Kluwer Academic Publishers

Casson, Mark. (1997), Information and Organization. Oxford: Oxford University Press.

Cheung, Stephen N.S. (1969), “The Structure of a Contract," Journal of Law and Economics 11:

Cheung, Stephen N.S. (1983), “The Contractual Nature of the Firm, " Journal of Law and Economics 26: 1-22.

Coase, Ronald H. (193), "The Nature of the Firm," Economica 4: 386-405, in Oliver E. Williamson and Sidney G. Winter. 1991. The Nature of the Firm, Oxford: Oxford University Press.

Coase, Ronald H. (1960), "The Problem of Social Cost," Journal of Law and Economics 3: $1-44$.

Coase, Ronald H. (1991), "The Nature of the Firm: Origin, Meaning, Influence," in Oliver E. Williamson and Sidney G. Winter. 1991. The Nature of the Firm, Oxford: Oxford University Press. 
David, P. (1987), "Some New Standards for the Economics of Standardization in the Information Age," in Partha Dasgupta and Paul Stoneman, eds. (1987) Economic Policy and Technological Performance, Cambridge: Cambridge University Press:

Demsetz, Harold. (1991), "The Theory of the Firm Revisited," in Oliver E. Williamson and Sidney G. Winter. 1991. The Nature of the Firm, Oxford: Oxford University Press.

Demsetz, Harold. (1995), The Economics of the Business Firm: Seven Critical Commentaries, Cambridge: Cambridge University press.

Eggertson, Thrainn. (1990), Economic Behaviour and Institutions, Cambridge: Cambridge University Press.

Foss, Kirsten. (1996), "Transaction costs and technological development: the case of the Danish fruit and vegetable industry," Research Policy 25:531-547.

Foss, Nicolai J. (1999), “The Use of Knowledge in Firms," Journal of Institutional and Theoretical Economics 155: 458-487.

Foss, Kirsten and Nicolai Foss. (2000a), "Assets, Attributes, and Ownership," forthcoming in International Journal of the Economics of Business.

Foss, Kirsten and Nicolai Foss. (2000b), "Theoretical Isolation in Contract Economics: Suppressing Margins and Entrepreneurship," forthcoming in Journal of Economic Methodology.

Galloway, Les. (1996), Operation Management: The Basics, London: International Thomson Business Press.

Grossman, Sanford, and Oliver Hart. (1986), "The Costs and Benefits of Ownership: A Theory of Vertical Integration," Journal of Political Economy 94: 691-719.

Hart, Oliver D. (1991), "Incomplete Contracts and the Theory of the Firm," in Oliver E. Williamson and Sidney G. Winter. 1991. The Nature of the Firm, Oxford: Oxford University Press.

Hart, Oliver. (1995), Firms, Contracts, and Financial Structure, Oxford: Clarendon Press.

Hayek, Friedrich A. von. (1945), "The Use of Knowledge in Society," in idem. Individualism and Economic Order, Chicago: University of Chicago Press.

Heiner, Ronald H. (1983), “The Origin of Predictable Behavior," American Economic Review 73: 560-595.

Jensen, Michael C. and William H. Meckling. (1992), "Specific and general Knowledge, and Organization a Structure", in Contrac Economics, ed. by Werin, Lars and Hans Wijkander, Oxford: Blackwell.

Klein, Benjamin, Robert G. Crawford, and Armen A. Alchian. (1978), "Vertical Integration, Appropriable Rents, and the Competitive Contracting Process," Journal of Law and Economics 21: 297-326.

Knight, Frank H. (1921), Risk, Uncertainty and Profit. 1965 reprint. New Your: Houghton-Mifflin. 
Langlois, Richard N. and Paul L. Robertson. (1995), Firms, Markets and Economic Change, London: Routledge.

Langlois, Richard N. and Nicolai J. Foss. (1999), “Capability and Governance: the Rebirth of Production in the Theory of Economic Organization," KYKLOS.

Leijonhufvud, Axel. (1986), "Capitalism and the Factory System," in Richard N. Langlois, ed. 1986. Economics as a Process: Essays in the New Institutional Economics. Cambridge: Cambridge University Press.

Loasby, Brian J. (1999), Institutions and Evolution in Economic Theory. London: Routledge.

Loasby, Brian J. (2000), "Cognition and Markets," paper for CRIC workshop on Market Relations and the Competitive Process.

Nelson, Richard R. and Sidney G. Winter. (1982), An Evolutionary Theory of Economic Change, Cambridge, MA: Belknap Press.

Penrose, Edith T. (1959), The Theory of the Growth of the Firm. Oxford: Oxford University Press.

Richardson, George B. (1972), “The Organisation of Industry," Economic Journal 82: 883-96.

Richardson, George B. (1975), "Adam Smith on Competition and Increasing Returns," in Andrew Skinner and Thomas Wilson, eds. Essays on Adam Smith. Oxford: Clarendon Press.

Romer, Paul M. (1986), “Increasing Returns and Long Run Growth," Journal of Political Economy 94: 1002-1037.

Rosen, Sherwin. (1991), "Transactions Costs and Internal Labor Markets" in Oliver E. Williamson and Sidney G. Winter. 1991. The Nature of the Firm, Oxford: Oxford University Press.

Rosenberg, Nathan. (1976), Perspectives on Technology, Cambridge: Cambridge University Press.

Sahal, Devendra. (1981), Patterns of Technological Innovation, Reading: AddisonWesley.

Stigler, George. (1951), "The Division of Labor is Limited by the Extent of the Market," Journal of Political Economy 59: 185-193.

Teece, David J. (1986), "Profiting from Technological Innovation," in Michael L. Tushman and William L Moore, eds. 1988. Readings in the Management of Innovation.

Tirole, Jean. (1999), “Incomplete Contracts: Where Do We Stand?”, forthcoming in Econometrica.

Wernerfelt, Birger. (1997), “On the Nature and Scope of the Firm: A Adjustment Cost Theory," Journal of Business.

Williamson, Oliver E. (1975), Markets and Hierarchies. New York: Free Press.

Williamson, Oliver E. (1985), The Economic Institutions of Capitalism. New York: Free Press. 
Yang, Xiaokai and Yew-Kwang Ng. (1993), Specializaton and Economic Orgaization. Amsterdam: North-Holland.

Young, Allyn. (1928), “Increasing Returns and Economic Progress," Economic Journal 38: 527-542. 